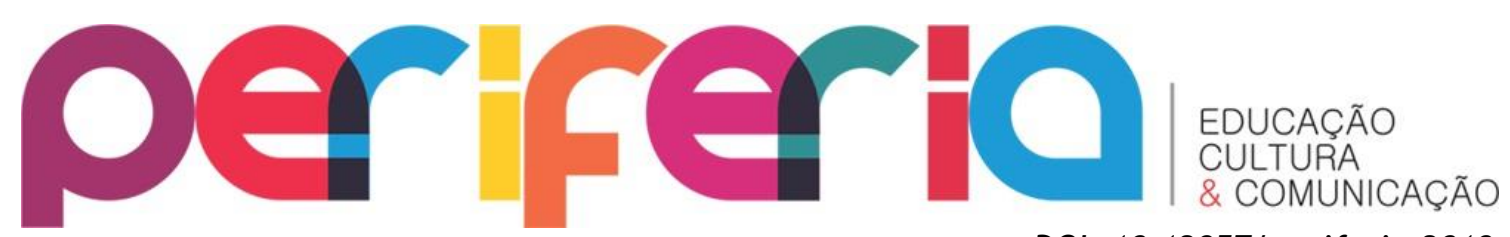

DOI: $10.12957 /$ periferia.2019.36408

\title{
OS MEMES COMO SUPORTE PEDAGÓGICO NO ENSINO DE HISTÓRIA
}

\author{
Diego Leonardo Santana Silva ${ }^{1}$ \\ Universidade Federal de Sergipe - UFS
}

\section{Resumo}

Este artigo tem como objetivo refletir acerca da possibilidade do uso de memes como um recurso pedagógico que aproxime professores e alunos em sala de aula a partir de uma linguagem digital comum. Sendo bastante popular no ciberespaço, os memes são elementos importantes na cultura digital e se popularizaram entre os jovens, sendo bastante eficientes em transmitir vários tipos de mensagens. Com isso, memes são utilizados para diversas finalidades, o que leva a reflexão sobre o uso dos mesmos como recurso didático. Levando em consideração as pesquisas sobre a inserção de recursos digitais em sala de aula, este artigo apresenta uma reflexão sobre essa questão, a partir de um estudo sobre os memes desde suas características básicas até o uso dos mesmos por páginas que abordam conteúdo histórico encontradas no Facebook. Por fim, será refletido sobre a possibilidade de uso e o papel que este recurso pode ter em sala de aula.

Palavras-chave: educação; ensino; história; meme

${ }^{1}$ Mestre em Educação - UFS. Graduado em História - UFS. Integrante do Grupo de Estudos do Tempo Presente (GET/UFS/CNPq). diego@getempo.org

Periferia, v. 11, n. 1, p. 162-178, jan./abr. 2019 


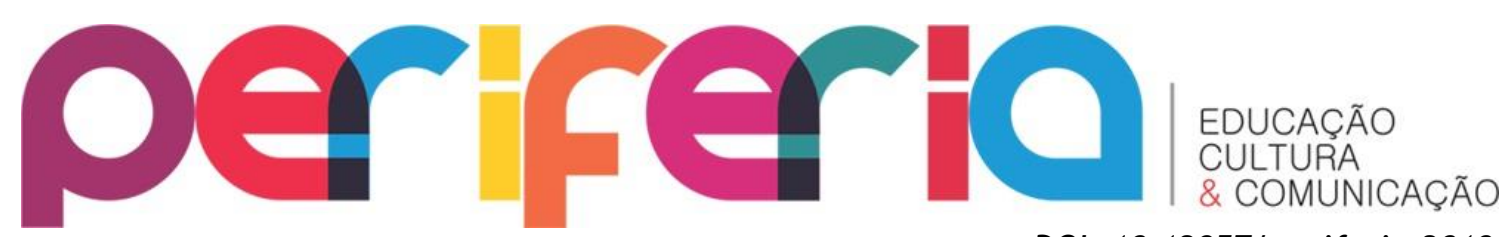

DOI: $10.12957 /$ periferia. 2019.36408

THE MEMES AS A PEDAGOGICAL SUPPORT IN THE TEACHING OF HISTORY

\begin{abstract}
This article propose a reflection about the possibility of using memes as a pedagogical resource that brings together teachers and students in the classroom from a common digital language. Being very popular in cyberspace, memes are important elements in digital culture and popularize among young people, being very efficient in transmitting various types of messages. With this, memes are used for various purposes, which leads to reflection on the use of them as didactic resource. Taking into consideration the research on the insertion of digital resources in the classroom, this article presents a reflection on this question, starting from a study about the memes from their basic characteristics to the use of them by pages that deal with historical content found in the Facebook. Finally, it will be reflected on the possibility of use and the role that this resource can have in the classroom.
\end{abstract}

Keywords: Education. History. Meme. Teaching. 


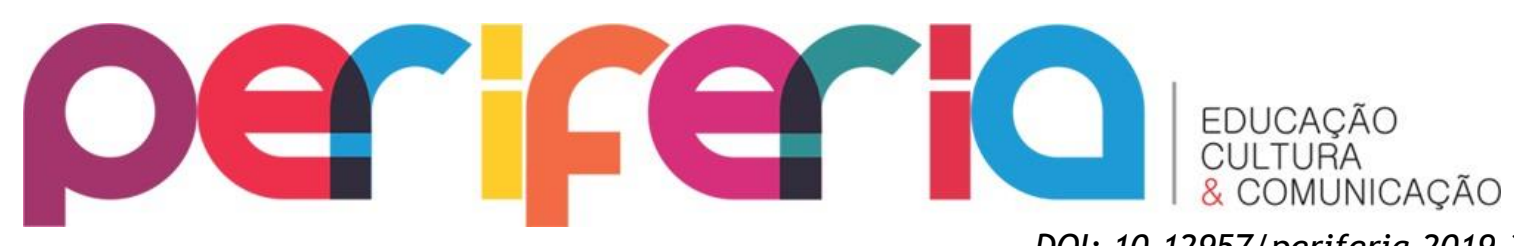

INTRODUÇÃO

DOI: $10.12957 /$ periferia.2019.36408

Uma das características mais marcantes da internet são os memes. Qualquer um que acesse a web já deve ter se deparado com algum. 0 modelo é simples e eficiente, geralmente eles transmitem alguma mensagem de maneira bem humorada e ganham repercussão se espalhando com facilidade. Em maior parte, produzido por jovens, a criação de memes é, para boa parte deles, um hobby enquanto outros conseguem fazer disso uma atividade lucrativa.

Este processo chamou atenção da BBC Brasil que em 2017 fez uma matéria sobre a chamada "profissionalização dos memes"2. Ao entrevistar criadores deste tipo de conteúdo, a matéria demonstrou que de um simples trabalho "amador" e colaborativo, as páginas se desenvolveram para algo lucrativo que se tornou interessante para atividades como, por exemplo, propaganda. Primeiro vem a página, depois com um grande número de seguidores é possível monetizar as postagens (BBC, 2017).

Uma das principais características dos memes virtuais é o bom humor. Recentemente, alguns ambientes que os usam para abordar conteúdo histórico vem surgindo nas redes sociais e ganhando milhares de seguidores. Um das mais famosas é chamada "História no Paint" e possui mais de 600 mil curtidas no Facebook ${ }^{3}$. 0 crescimento deste tipo de página ocorre em um momento específico. A escola das duas primeiras décadas do século XXI lida com um problema: como os professores devem trabalhar em sala de aula com alunos que, como veremos mais adiante, são verdadeiros nativos digitais?

O campo educacional está repleto de pesquisas referentes a estratégias de ensino que tornem a sala de aula atraente a estes estudantes. Os estudantes são nativos digitais, mas há também professores nativos digitais e outros professores e pesquisadores que são migrantes digitais, ou seja, pessoas que não nasceram

\footnotetext{
2 Disponível em: https://www.bbc.com/portuguese/salasocial-39402172. Acesso em 25/06/2018 às 18 horas e 44 minutos.

${ }^{3} \mathrm{O}$ número de seguidores de uma página no facebook varia diariamente. Deste modo, optou-se por um número aberto e não fechado para exemplificar a quantidade de seguidores. Este artifício será usado quando outras páginas forem abordadas neste artigo. Para consultar a página "História no Paint" ver: https://www.facebook.com/Historianopaint/. Acesso em 26/06/2018 às 19 horas e 05 minutos.
}

Periferia, v. 11, n. 1, p. 162-178, jan./abr. 2019 


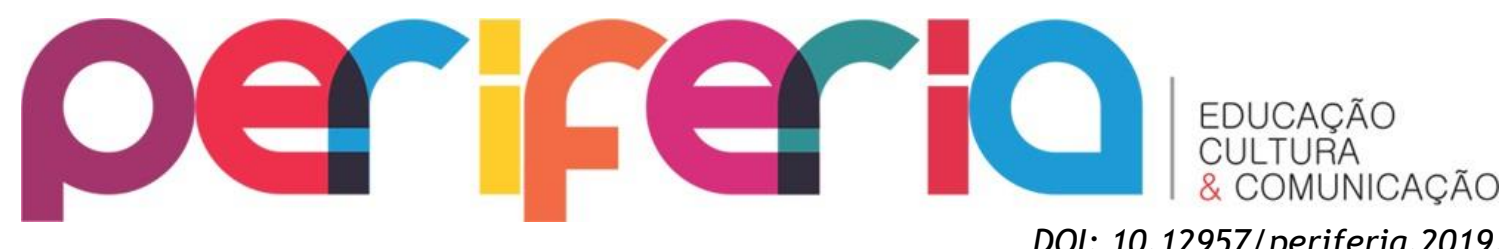

DOI: $10.12957 /$ periferia.2019.36408 inseridos em uma cultura digital e que foram se inserindo na mesma ao decorrer da vida (PRENSKY, 2001). Em meio a este importante debate, este artigo apresenta uma reflexão acerca de uma instigante proposta: seria possível utilizar os tão populares memes como recursos pedagógicos? Caso a resposta seja sim, qual seria o papel deles?

\section{OS MEMES E A CIBERCULTURA}

Definida por Pierre Lévy como “o conjunto de técnicas (materiais e intelectuais), de práticas, de atitudes, de modos de pensamento e valores que se desenvolvem juntamente com o crescimento do ciberespaço" (2014, p.17), a cibercultura está em constante transformação. Ao navegar pelo ciberespaço, novos ambientes emergem enquanto outros se atualizam criando cada vez mais conteúdo que variam de páginas pessoais, comerciais, governamentais etc, o que gerou uma overdose de informação.

É tanto conteúdo criado que levou a reflexão de pesquisadores. Alguns afirmaram que estamos navegando em meio a um “Dilúvio de Dados". Conforme explica Dilton Maynard, foi Roy Ascott quem cunhou este termo que se refere a uma analogia ao dilúvio narrado na bíblia. Ainda segundo Maynard:

Porém, ao contrário dos tempos de Noé, as águas do novo dilúvio são formadas por dados, notícias, imagens, músicas e tudo o mais que circula no universo eletrônico. O oceano agora é feito de informações. Este novo lugar tem a sua melhor forma de representação naquilo que hoje chamamos Internet. (MAYNARD, p.1, 2011)

Se guiar em meio a este dilúvio faz seus navegantes recorrerem a recursos que filtrem aquilo que eles querem acessar neste imenso ambiente. Evidentemente, filtrar esta informação seria mais difícil sem o uso de recursos como os famosos buscadores (Google, Bing e Yahoo). Basta o internauta inserir aquilo que se deseja saber que estas ferramentas fazem esta busca na rede apresentando milhares de sites, blogs ou notícias que abordem o tema escolhido. Costuma-se falar que é possível aprender quase qualquer coisa na internet desde livros até mesmo simples 


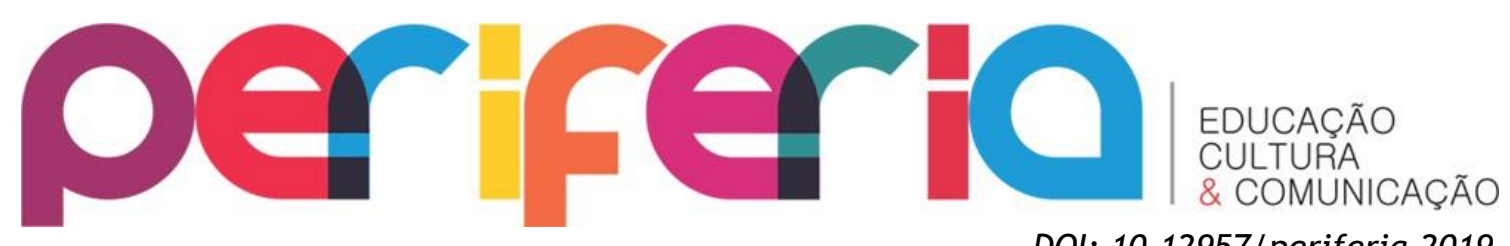

DOI: $10.12957 /$ periferia. 2019.36408

tutoriais no Youtube que ensinam coisas que vão desde um conceito filosófico ou mesmo tarefas como, por exemplo, abrir uma porta quando se perdeu a chave, cozinhar, enfim é possível aprender um pouco de quase tudo.

Essa facilidade leva a crer por um lado que a internet abre horizontes, possibilitando a qualquer pessoa encontrar aquilo que deseja, fazendo com que esta mídia seja vista por alguns como mais democrática que outras. Por outro lado, redes sociais e serviços de streaming ${ }^{4}$ moldam o conteúdo que é apresentado a seus usuários criando "bolhas”, assimilando um conteúdo a outro favorável, filtrando aquilo que é apresentado a seus usuários (PARISER, 2012). Isso ocorre porque a quantidade de conteúdo é tão diversificado que o usuário pode acabar lidando com algo que não deseje. Como o objetivo dos sites é que quem os acesse passe o máximo de tempo neles, a personalização do conteúdo é um recurso para torná-las mais agradáveis. Ou seja: a internet é imensa e navegar por ela está cada vez mais personalizado de acordo com aquilo que o usuário deseja. Invés da mesma ser usada para ampliar horizontes, a rede acabou sendo utilizada também para inserir pessoas em bolhas.

É neste ciberespaço que os memes estão inseridos. Para entender o que eles são, primeiramente devemos retornar aos estudos do biólogo Jacques Monod, ganhador do prêmio Nobel em 1965. Ele trabalhava com uma ideia de que havia um "reino abstrato", habitado pelas ideias, que estava pairando sobre a biosfera" (GLEICK, 2013, p.320). As ideias teriam um poder de contágio e de se proliferar. Para Richard Dawkins, as ideias se disseminam tendo como protagonista o replicador que ele denominou como sendo o “meme” (GLEICK, 2013, p. 321). Ao explicar este processo, James Gleick afirmou que os memes se replicam de um cérebro para outro seja como ideias, frases de efeito, ritmos e rimas ou imagens, sendo os memes "unidades complexas, distintas e memoráveis - unidades com poder de permanência" (2013, p. 322).

\footnotetext{
${ }^{4}$ Streaming é uma forma de transmitir conteúdo na rede, principalmente arquivos sonoros e áudio visuais como músicas, filmes e podcasts diretamente da rede, a partir do acesso, sem que seja necessário realizar download do conteúdo. Este tipo de serviço se popularizou nos últimos anos com empresas como Netflix e Spotify ganhando milhões de usuários.
}

Periferia, v. 11, n. 1, p. 162-178, jan./abr. 2019 


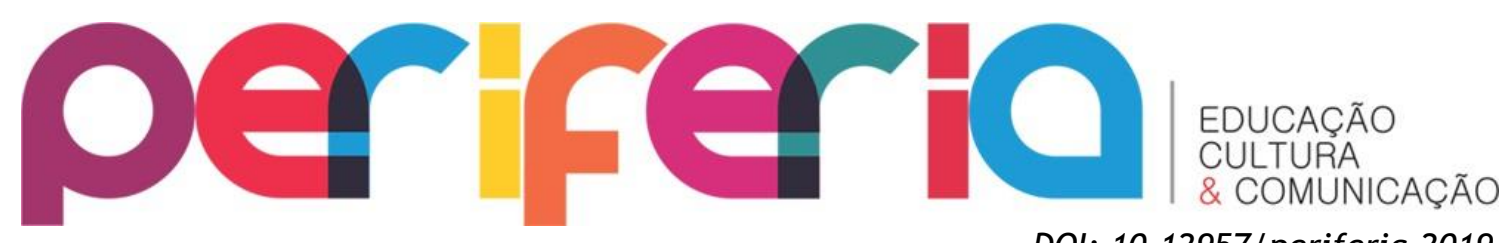

Em um ciberespaço tomado por um “Dilúvio de Dados”, os memes podem destacar uma mensagem, fazendo com que a mesma ganhe grande repercussão. Eles estão presentes na internet desde os primórdios da rede. Antes eles eram mais populares em correntes de e-mail. Um dos casos mais famosos foi o de uma corrente de e-mail que ocorreu na virada do milênio, quando "se espalhou em escala global a crença de que os computadores de todo o mundo gaguejariam ou se engasgariam assim que seus relógios internos chegassem a um número redondo" (GLEICK, 2013, p.331).

Atualmente os memes mais populares na rede não são mais repassados por email e sim compartilhados em redes sociais ou aplicativos de mensagens. Diferentemente dos textos das correntes de e-mail, são utilizadas imagens. Isso ocorre devido à facilidade de edição existindo, inclusive, sites para que se criem memes. Um exemplo de site deste tipo é o Meme Generator (https://imgflip.com/memegenerator), nele é possível escolher uma imagem e inserir um texto na mesma criando assim um meme. A disseminação das imagens nos memes ocorre porque ela tem a função de expressar uma ação seja ela de felicidade, tristeza, ironia, irreverência etc. Sendo assim, uma imagem pode ser inserida e compreendida em contextos variados, sendo transmitidas em diferentes espaços e absorvidas em ambientes distintos.

A base da mensagem é uma imagem usada para expressar aquilo que se deseja. Seu uso varia a depender do objetivo. Geralmente é escolhida uma determinada imagem e coloca-se alguma mensagem nelas como será demonstrado no exemplo a seguir: 


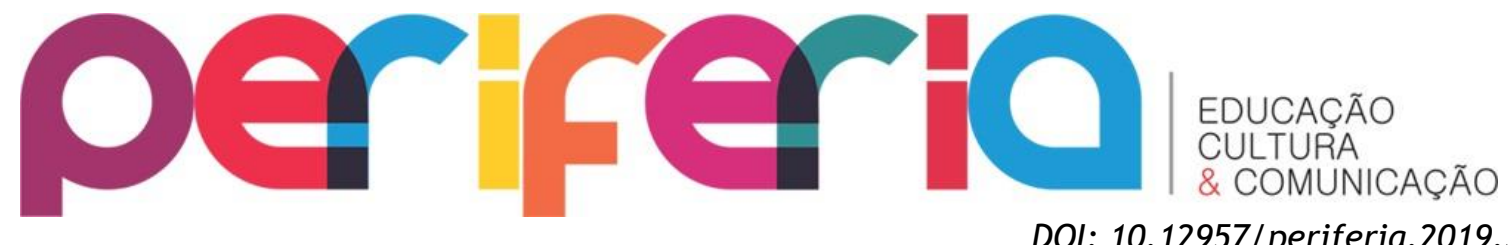

Imagem 1

DOI: $10.12957 /$ periferia.2019.36408

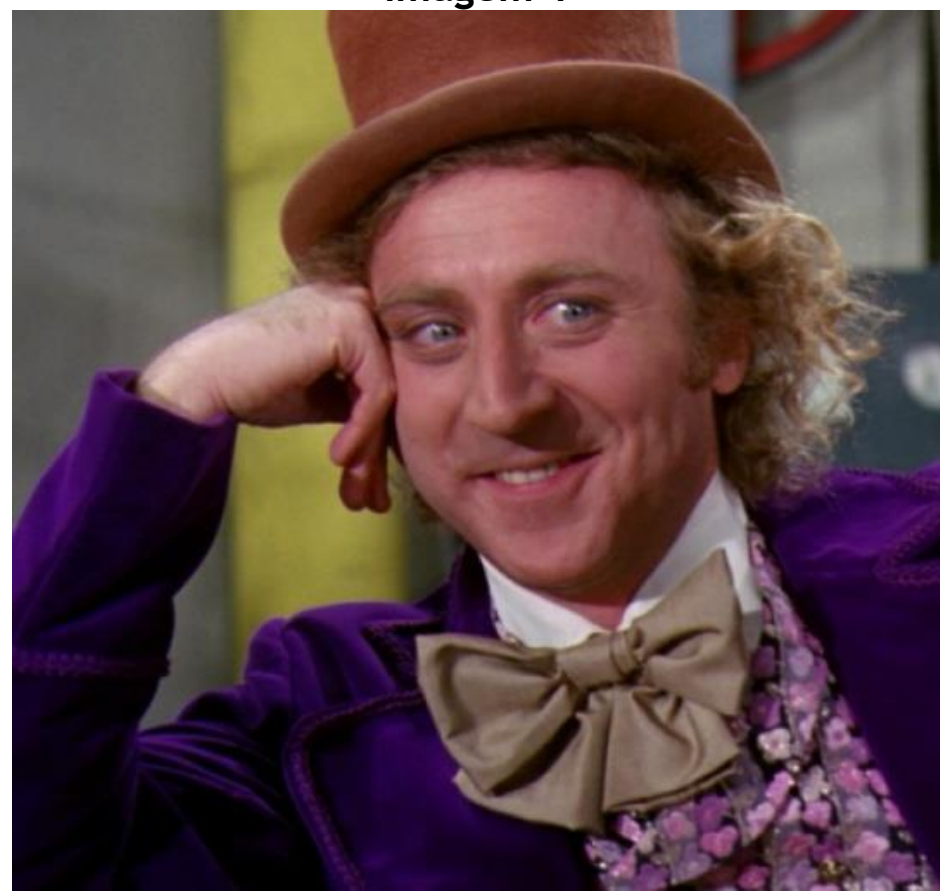

Disponível em: https://imgflip.com/memegenerator/Creepy-Condescending-Wonka

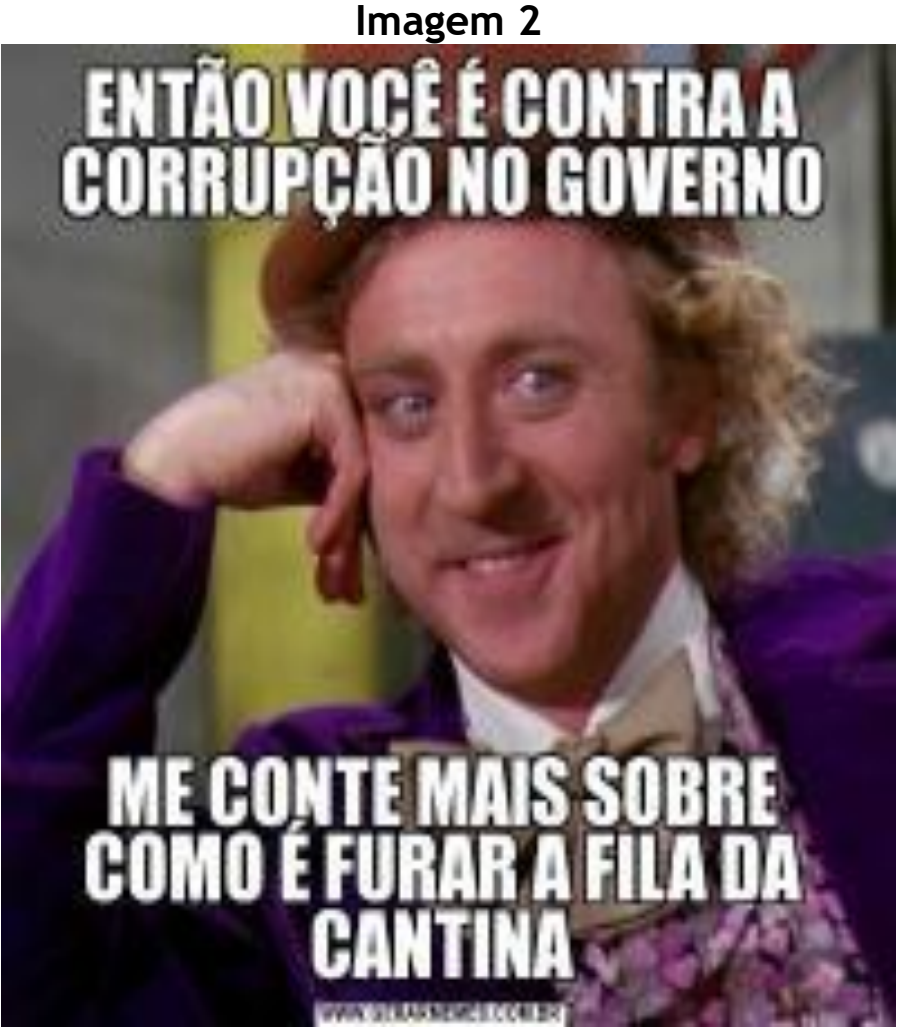

Disponível em: https://www.gerarmemes.com.br/criar-meme-galeria/307-willy-wonkaironico

Periferia, v. 11, n. 1, p. 162-178, jan./abr. 2019 


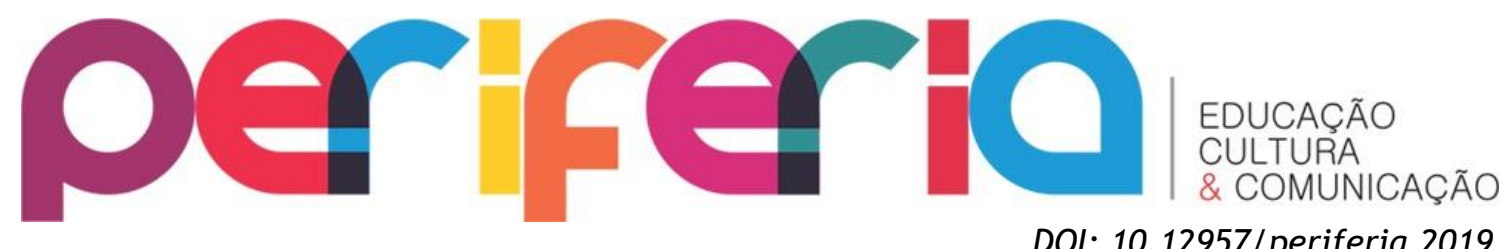

DOI: $10.12957 /$ periferia. 2019.36408

O exemplo apresentado aqui é o famoso meme do icônico personagem Willy Wonka ironizando a seletividade da indignação a respeito da corrupção. A mensagem é bastante clara e é transmitida de maneira irônica e bem-humorada. A expressão irônica da imagem encaixa perfeitamente em seu objetivo fazendo com que ela seja compreendida com facilidade. É difícil especificar se há um tempo de duração de um meme e os critérios para a escolha das imagens, já que cada grupo de memes pode escolher imagens específicas para cada caso. Isso ocorre porque determinadas imagens farão sentido em um contexto enquanto outras não. Por exemplo, um estudante de história poderia entender melhor um meme que usasse uma imagem de um importante historiador enquanto estudantes de química compreenderiam melhor algum meme que usasse uma fórmula de elementos da tabela periódica. Além disso, esse tipo de meme surge para refletir sobre algo que ocorreu naquele momento, havendo múltiplas formas e objetivos para criá-los. Por isso a duração dos mesmos é tão difícil de especificar porque suas características carregam consigo aspectos do momento em que os mesmos surgiram.

O uso dos memes é adaptado para cada situação de modo que há uma diferença entre a imagem e a mensagem textual já que a imagem pode ser utilizada para replicar qualquer mensagem textual. Desse modo, uma mesma imagem pode render memes diferentes a depender da forma a qual a mesma é utilizada.

\section{DISSEMINANDO MEMES}

Como sabemos, especificar o tempo que um meme dura ou o critério de escolha das imagens é uma atividade complexa. Porém, em meio às múltiplas iniciativas de interação e produção de conteúdo no ciberespaço, surgem ambientes específicos com memes temáticos. Ou seja, uma página para trabalhar um certo tipo de meme, visando um público específico. Aplica-se aqui a mesma lógica de criação de um site ou blog com cada ambiente atendendo a uma demanda que varia de acordo tanto com o público que se deseja atingir quanto às preferências de quem cria as páginas. 


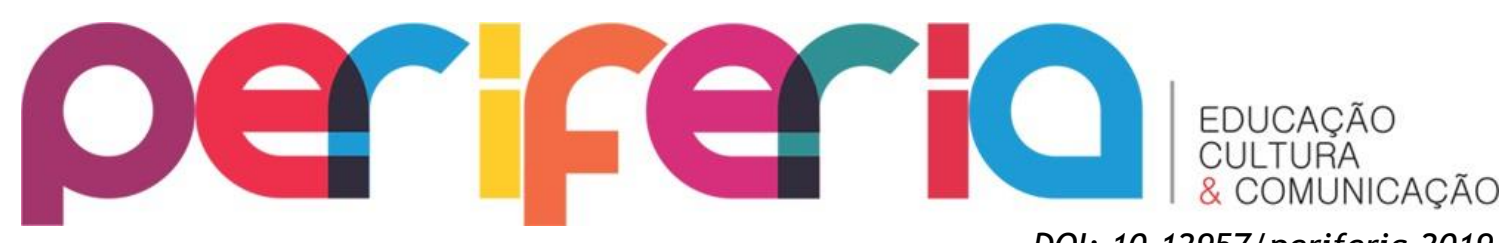

DOI: $10.12957 /$ periferia. 2019.36408

Um dos locais mais usados para criar páginas com memes é o Facebook, o que é de se esperar já que esta é a rede social mais acessada no mundo ${ }^{5}$. Dentre as várias páginas que usam memes relacionados a temas históricos no facebook, uma das famosa delas é a "História no Paint" (https: //www.facebook.com/Historianopaint/) com mais de 600 mil curtidas. A mesma atua diariamente postando memes que abordam conteúdos históricos de maneira bem humorada. Tendo em vista a grande variedade de memes, faz-se necessário especificar que essa e outras páginas se apropriam das imagens de memes já existentes mudando o texto para uma situação histórica. Eis um exemplo:

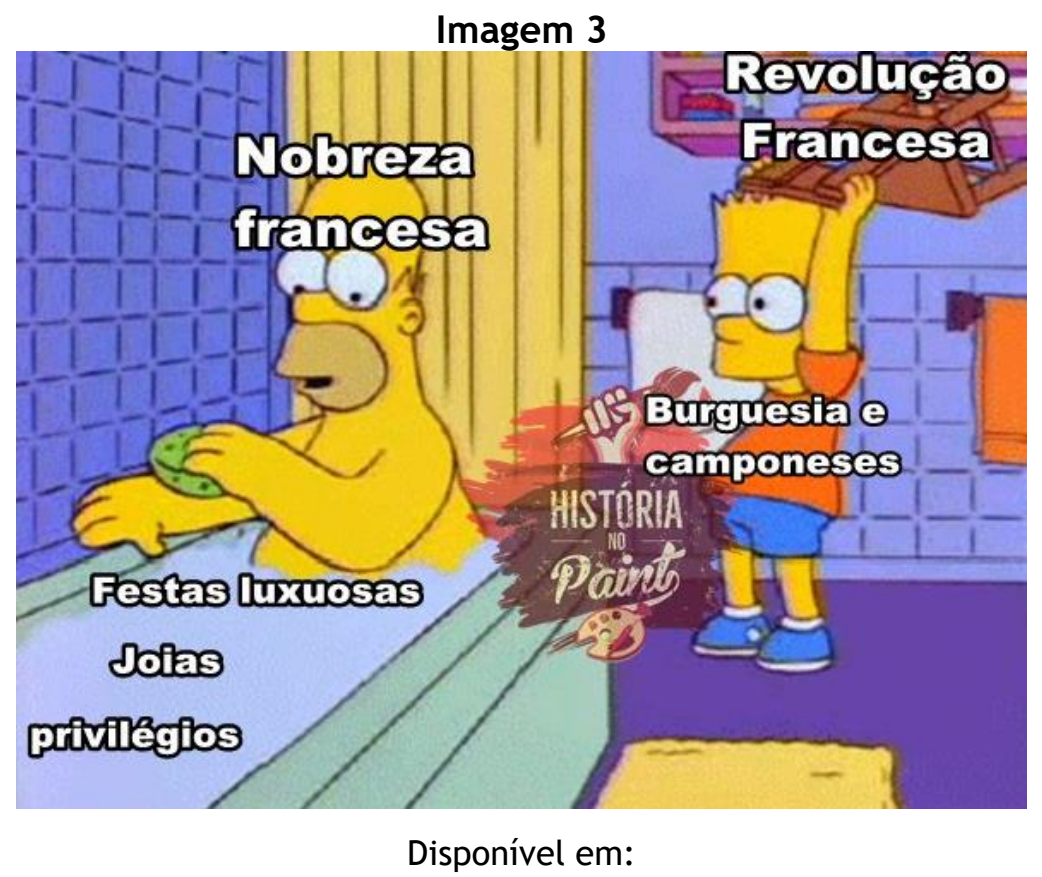

https://www.facebook.com/Historianopaint/photos/a.483753418343348.122861.251332234918802/ $1830784103640266 /$ ?type=3\&theater.

A Imagem 3 é referente a um meme que retrata de maneira cômica uma situação ocorrida na série de TV “Os Simpsons”. A situação é clara, enquanto o personagem Homer está despreocupado tomando banho em uma banheira o personagem Bart se prepara para jogar uma cadeira em suas costas. Este meme serve para retratar uma situação na qual, enquanto alguém está despercebido, outro se

${ }^{5}$ Segundo matéria do portal Tech Tudo, o facebook lidera o ranking das redes sociais mais acessadas
no mundo em 2017. Para mais informações consultar: https: / / www.techtudo.com.br/noticias/2017/07/facebook-domina-ranking-de-redes-sociais-maisusadas-no-mundo.ghtml. Acesso em 04/07/2018 às 17 horas e 19 minutos.

Periferia, v. 11, n. 1, p. 162-178, jan./abr. 2019 


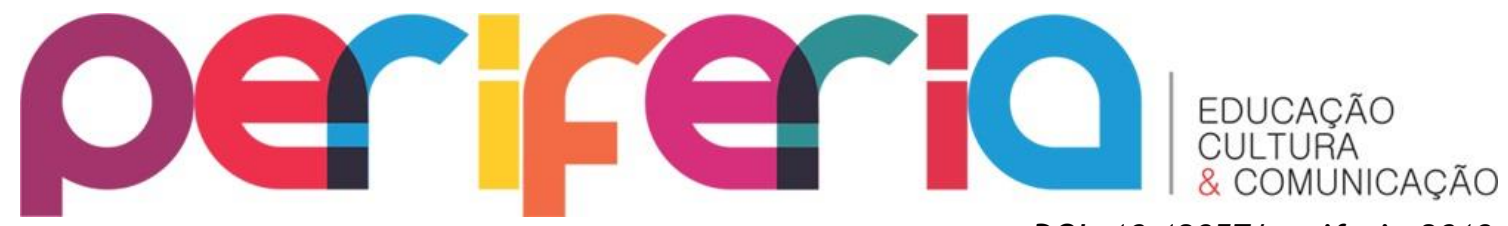

DOI: $10.12957 /$ periferia.2019.36408 prepara para dar-lhe um golpe. Como apresentado, o meme se torna uma sátira de como a França pré-revolucionária se encontrava antes dos eventos de 1789 . A displicência da nobreza francesa, preocupada com suas festas luxuosas e seus privilégios é ironizada na figura do Homer enquanto o Bart representa a burguesia e o campesinato prestes a derrubar o regime.

Para compreender a piada é necessário saber do que ela se trata. Ou seja, se a pessoa não souber algo, nem que seja mínimo, sobre o tema a mesma dificilmente compreenderá este meme. É válido lembrar que o conteúdo de história é inserido no meme e não o contrário. Ou seja, a mensagem é aplicada em uma imagem antes existente que reflete uma determinada situação. Aqui podemos observar a criatividade para produzir uma mensagem com um conteúdo que atende às demandas da página, com o meme aqui apresentado servindo como um bom exemplo do processo de criação de memes aqui comentado.

Porém, não é apenas dessa maneira que os memes são trabalhados. Eles também podem ser postados em separado, dialogando com uma mensagem já existente que viralizou na rede. Usaremos um exemplo ainda da página "História no Paint":

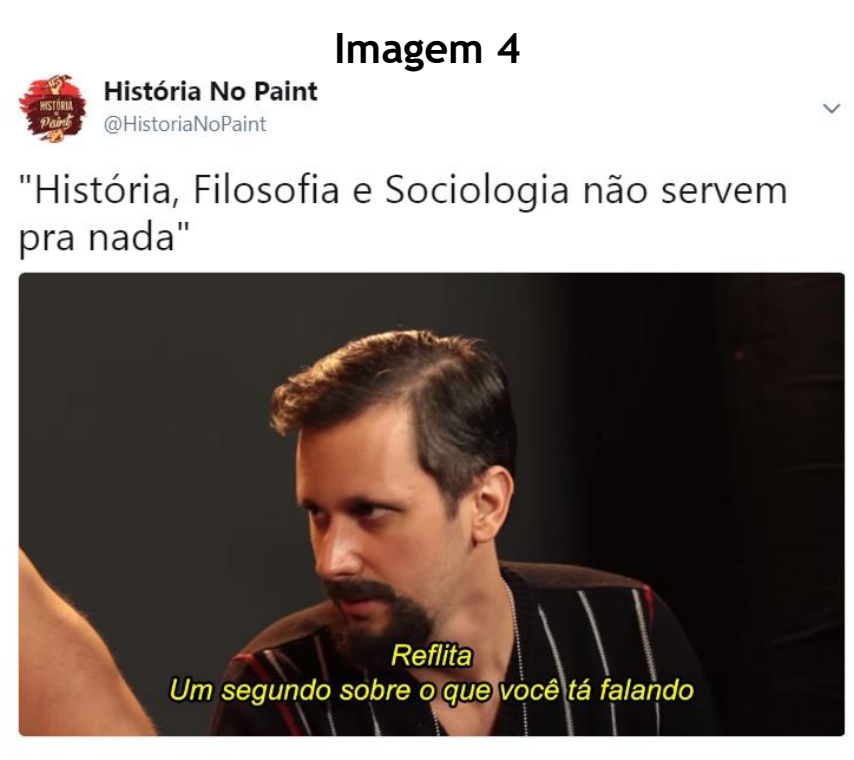

19:34 - 17 de abr de 2018

Disponível em:

https://www.facebook.com/Historianopaint/photos/a.483753418343348.122861.251332234918802/ $1809419645776712 /$ ?type=3\&theater. 


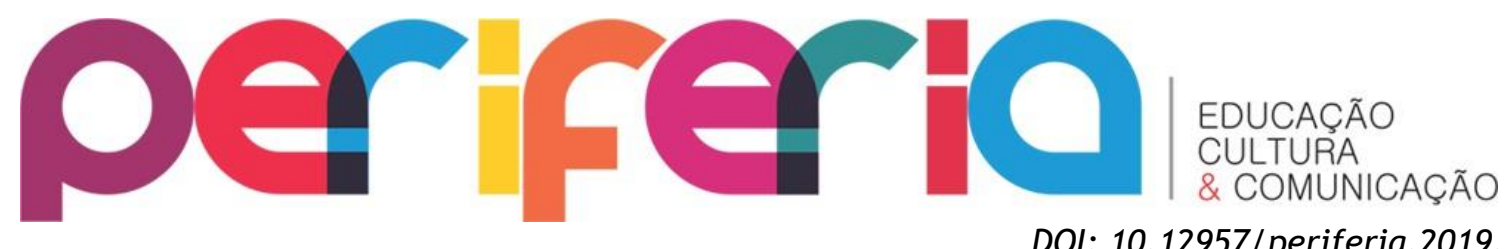

DOI: $10.12957 /$ periferia.2019.36408

A postagem traz uma mensagem que contesta a importância de História, Sociologia e Filosofia sendo rebatida por um meme do personagem Renan do programa "Choque de Cultura". O meme aqui é mantido em sua forma original, ou seja, a mensagem extraída da fala do personagem Renan em um episódio do programa "Choque de Cultura" é mantida e usada para refutar uma ideia considerada errada pela página. Este exemplo serve para compreendermos que o meme nas redes sociais pode se manifestar em forma de imagem, imagem e texto pré-determinado ou imagem e texto escrito para uma situação específica. Aqui o meme é a imagem e mensagem escrita "Reflita um segundo sobre o que você tá falando" que é adaptado para contrapor uma situação. Desse modo, observamos a variedade de como estes memes podem ser utilizados.

Nos dois exemplos aqui apresentados é possível ver tanto a construção de um meme (imagem 3) quanto o diálogo com outro (imagem 4). Ambas as iniciativas abordam alguma questão pertinente de maneira bem humorada, mas também com um alcance interessante. Por serem familiar ao tipo de conteúdo que repercute nas redes, as postagens se disseminam com mais facilidade. A imagem 3 alcançou mais de 5 mil compartilhamentos ${ }^{7}$ enquanto a imagem 4 chegou a mais de 3 mil $^{8}$ o que demonstra um bom alcance destas publicações. A repercussão destes memes são exemplos de disseminação de uma forma de conhecimento já que além da criação destes memes em especial há também o alcance dos mesmos.

Compreender o que está por trás da difusão deste tipo de memes remete a uma discussão sobre como compreendemos este processo. Ao analisá-lo, o termo “popularização” vem à mente, porém o uso do mesmo pode ser problemático já que

6 Choque de cultura é um programa de humor produzido pelo canal "TV Quase" (https://www.youtube.com/channel/UC033rpv70Kk-QYfrvwl5s8Q) e apresentado no mesmo e também no canal "Omelete" (https://www.youtube.com/user/omeleteve), ambos no Youtube. É um programa de humor que retrata uma situação no qual quatro motoristas de van conversam sobre cultura, principalmente cinema. A forma a qual eles abordam este e outros temas renderam situações engraçadas com o programa ganhando repercussão e gerando memes que se popularizaram.

${ }^{7}$ Assim como o número de seguidores a quantidade de compartilhamentos e curtidas também varia. Portanto esse é um número arredondado no momento de escrita deste artigo. Disponível em: https: / / www. facebook.com/Historianopaint/photos/a.483753418343348.122861.251332234918802/ $1830784103640266 /$ ?type=3\&theater. Acesso em 02/07/2018 às 22 horas.

${ }^{8}$ Assim como o número de seguidores a quantidade de compartilhamentos e curtidas também varia. Portanto esse é um número arredondado no momento de escrita deste artigo. Disponível em: https://www.facebook.com/Historianopaint/photos/a.483753418343348.122861.251332234918802/ $1809419645776712 /$ ?type=3\&theater. Acesso em 02/07/2018 às 21 horas e 53 minutos.

Periferia, v. 11, n.1, p. 162-178, jan./abr. 2019 


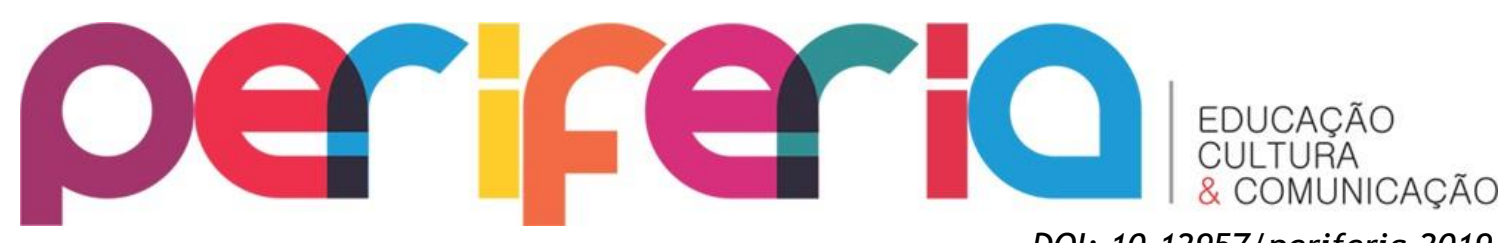

ele é considerado simplório. Ao estudar a disseminação dos conhecimentos em sua obra “Uma História Social do Conhecimento II", Peter Burke explicou que:

Para um especialista, qualquer forma de falar ou escrever para não especialistas é uma espécie de “popularização". O problema é que esses não especialistas não compõem um grupo culturalmente homogêneo. O modelo binário de "elite" e "povo" é simplista demais, como os historiadores da cultura popular descobriram uma geração atrás. É preciso distinguir vários graus de distância cultural e diversos públicos ou audiências (BURKE, 2012, p.113)

Sendo assim, devido à diversidade de integrantes e à compreensão de que públicos diferentes absorvem e consomem conhecimentos de formas diferentes alguns autores preferem usar o termo “exposição” invés de “popularização” (BURKE, 2012, p,113). Além disso, Burke também chama atenção ao fato de que a exposição não é um simples processo de transmissão da informação de um emissário a um receptor, com este processo sendo demasiadamente esquemático (2012, p.113). Se os públicos são diferentes, a maneira a qual cada um consome conhecimentos também é diferente, basta lembrar que, após a exposição de uma aula alguns alunos apresentarão questionamentos diferentes sobre o conteúdo explanado.

Isso também serve para analisar a exposição dos memes no ciberespaço. 0 público que curte páginas como a "História no Paint" apresentada anteriormente neste artigo é variado embora é de se acreditar que, devido ao modelo da página este seja em sua maioria jovens ${ }^{9}$. Em um momento no qual estas práticas ganham tantos adeptos é válido refletir sobre a possibilidade de usar esse tipo de coisa como recurso pedagógico.

\footnotetext{
${ }^{9}$ Para quem não tem acesso como administrador da página é difícil especificar o perfil exato dos seguidores da mesma devido ao fato dos usuários comuns destas páginas não terem acesso a estes dados. Todavia, há de se acreditar que o perfil dos mesmos seja majoritariamente jovem devido ao conteúdo da mesma, baseada em memes e às informações contidas em matérias jornalísticas como a da BBC Brasil utilizada neste artigo.
}

Periferia, v. 11, n. 1, p. 162-178, jan./abr. 2019 


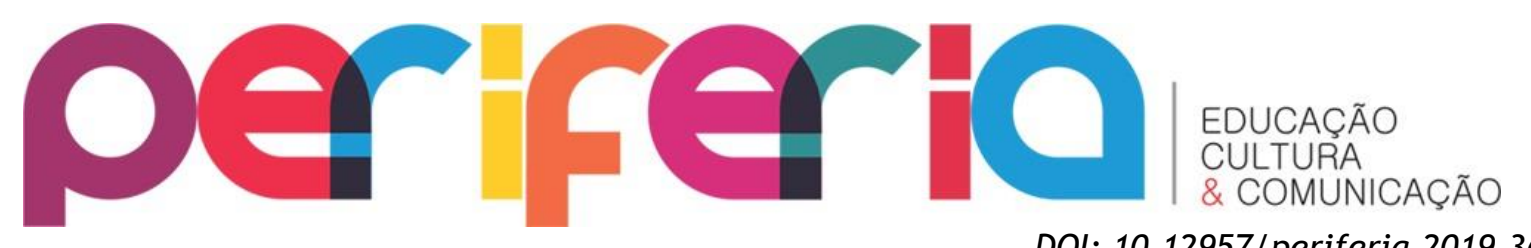

OS MEMES COMO SUPORTE PEDAGÓGICO

DOI: $10.12957 /$ periferia.2019.36408

Para explanar como os memes encontrados no ciberespaço podem ser utilizados como um suporte pedagógico, é necessário nos situarmos em meio a um debate um pouco mais amplo, referente a maneira a qual estudantes se relacionam com os recursos digitais.

Primeiramente, compreendemos que há um perfil, não tão novo assim, de estudantes que são familiarizados com recursos digitais. Este processo ocorre desde os anos 2000, ou mesmo, a depender da região, desde os anos finais da década de 1990. Foi nessa época que recursos como computadores e videogames se popularizaram, se tornando objetos comuns a muitos adolescentes. Surgiu uma geração a qual o pesquisador norte-americano Marc Prensky denominou como “nativos digitais". Em um artigo intitulado Digital Natives, Digital Immigrants $(2001)^{10}$, Prensky refletiu sobre o que para ele era um grande desafio educacional nos Estados Unidos daquela época. Este desafio consistia no fato de os alunos serem digitais (nativos digitais) e os professores serem analógicos (migrantes digitais). Havia um choque de gerações que fazia com que estudantes acostumados aos recursos digitais tivessem que lidar com uma escola analógica que poderia se tornar desinteressante para eles (PRENSKY, 2001).

Surgiu um novo perfil de aluno, que está inserido em uma cultura digital, sendo produtor e reprodutor da mesma e que se depara, em muitos casos, com uma escola que, para alguns, ainda é analógica. Evidentemente, é de se imaginar que professores e pesquisadores não estejam de braços cruzados quanto a isso. Uma pesquisa coordenada pelo movimento “Todos Pela Educação" que foi publicada em 2017 questionou professores da rede pública de ensino no Brasil sobre o uso de tecnologias em sala de aula ${ }^{11}$. Foram ouvidos 4 mil professores em todo país. Destes, $55 \%$ informaram que usam regularmente alguma tecnologia digital em sala de aula,

$10 \quad$ Disponível em: http://www.marcprensky.com/writing/Prensky\%20\%20Digital\%20Natives,\%20Digital\%20Immigrants\%20-\%20Part1.pdf. Acesso em 17/07/2018 às 14 horas e 14 minutos.

11 Dados da pesquisa estão disponíveis em: http://fundacaotelefonica.org.br/noticias/pesquisasobre-uso-de-tecnologia-nas-escolas-aponta-principais-desafios-que-educadores-enfrentam-na-salade-aula/. Acesso em 14/07/2018 às 17 horas e 37 minutos.

Periferia, v. 11, n. 1, p. 162-178, jan./abr. 2019 


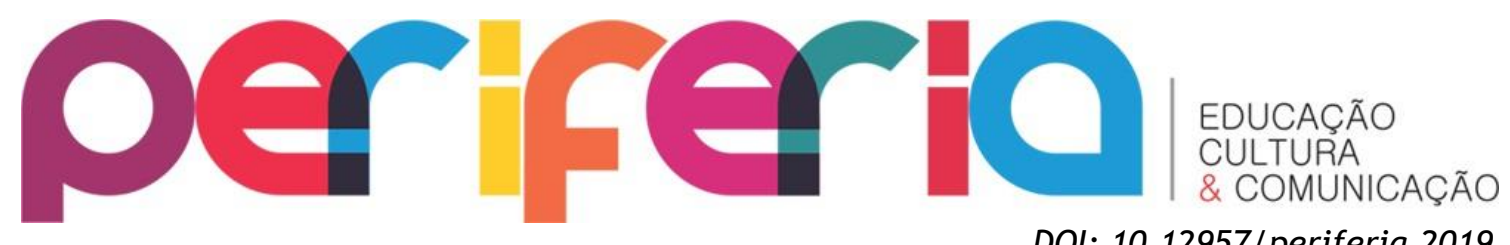

DOI: $10.12957 /$ periferia. 2019.36408 com os dados publicados levando a crer que este número só não e maior devido à falta de estrutura nas escolas (FUNDAÇÃO TELEFONICA, 2017). Este número representa que mais da metade dos professores buscam inserir recursos digitais em suas aulas, o que leva a um famoso questionamento popular: o copo está meio cheio ou meio vazio? Observando o crescimento ocorrido nos últimos anos, compreende-se aqui que estamos caminhando, mesmo que alguns achem que seja aos poucos, para uma inserção cada vez maior destes recursos em sala de aula.

Desse modo, podemos situar que tanto alunos quanto professores estão cada vez mais inseridos em uma cultura digital. Em uma época na qual recursos digitais são cada vez mais consumidos, a familiarização com os mesmos se torna cada vez mais evidente, o que leva a questionamentos quanto às características deste processo. Para pensar o mesmo nos deparamos muito com o termo "cultura digital". Em um artigo intitulado Creativity, Innovation and Digital Culture. A Map of Interactions publicado na revista Telos em 2014 ${ }^{12}$, sociólogo Manuel Castells apresenta seis características para entendermos a cultura digital, que são:

1. Habilidade para comunicar ou mesclar qualquer produto baseado em uma linguagem digital comum;

2. Habilidade para comunicar desde o local até o global em tempo real e vice-versa, para poder diluir o processo de interação;

3. Existência de múltiplas modalidades de comunicação;

4. Interconexão de todas as redes digitalizadas de base de dados ou a realização do sonho do hipertexto do Nelson, com o sistema de armazenamento e recuperação de dados chamado Xanadú em 1965;

5. Capacidade de reconfigurar todas as configurações, criando um novo sentido nas diferentes camadas dos processos de comunicação; 6. Criação gradual da mente coletiva pelo trabalho on-line, mediante um conjunto de cérebros sem limite algum. (CASTELLS, 2014) $)^{13}$

12

Disponível

em:

https://telos.fundaciontelefonica.com/telos/articulocuaderno.asp@idarticulo=3.htm. Acesso em $14 / 07 / 2018$ às 18 horas e 27 minutos.

${ }^{13}$ Do original: 1.- Ability to communicate or mix any product based on a digital common language. 2.Ability to communicate from the local to the global in real time, and vice versa, in order to blur the interaction process. 3.- Existence of multiple modes of communication. 4.- Interconnection of all data bases digitalized networks or the achievement of Nelson's hypertext dream with the storage and retrieving data system called "Xanadu" in 1965. 5. - Capacity to reconfigure all configurations creating a new meaning in the different multilayers of the communication processes. 6.- Gradual creation of a collective mind due to online work through a set of brains without any limits. At this stage, I am referring to connections between online brains and the collective mind. (CASTELLS, 2014) Tradução nossa.

Periferia, v. 11, n. 1, p. 162-178, jan./abr. 2019 


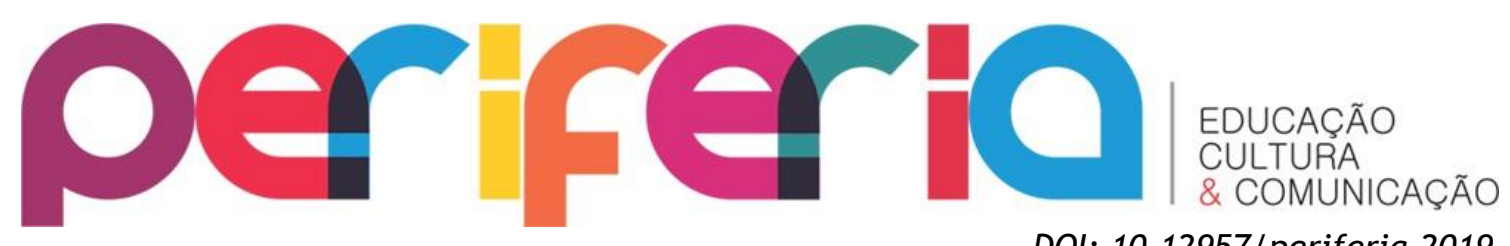

DOI: $10.12957 /$ periferia.2019.36408

Algumas dessas características podem ser bem utilizadas na educação como no caso do uso dos hiperlinks apontados na quarta característica. Já em relação ao uso de memes como suporte pedagógico, que é o tema deste artigo, este processo dialoga com a primeira e com a quinta característica. Ou seja, com a habilidade de se comunicar em uma linguagem digital comum $\left(1^{\circ}\right)$, neste caso, o meme serve como uma linguagem comum, reconhecida por seus usuários. Já sobre a capacidade de reconfigurar todas as comunicações criando sentidos diferentes $\left(5^{\mathrm{a}}\right)$, percebe-se isso no uso da mesma imagem para produzir memes diferentes. Sendo assim, a criação e recepção dos memes faz parte dessa cultura digital tão presente na atualidade.

Devido a essas características, os memes podem ser usados como um recurso didático. Compreendemos recuso didático como "todo material utilizado como auxílio no ensino-aprendizagem do conteúdo proposto para ser aplicado pelo professor a seus alunos" (SOUZA, 2007, p.111). Como vimos neste artigo, os memes tem um incrível poder de replicar mensagens e para compreende-los é necessário está inserido no ambiente que o mesmo se prolifera. Em uma época em que estudantes estão cada vez mais familiarizados com esse tipo de linguagem, o uso da mesma para assimilar conteúdo representa uma válida iniciativa como maneira de trazer professores e alunos a uma linguagem digital comum. Não se trata de fazer com que os memes sejam o principal recurso didático e sim refletir sobre o fato de que, em meio a diversos recursos digitais, os memes podem ser uma ferramenta interessante neste processo. Sendo assim, os mesmos se tornam recursos interessantes no processo analisado neste artigo.

\section{CONCLUSÃO}

Atualmente, professores tendem a pensar novas formas para se aproximados alunos. Utilizar um recurso tão popular entre eles, como os memes, pode ser uma maneira de realizar isso. Evidentemente que não está sendo proposto aqui que se deva ensinar a partir apenas disso ou que os memes podem ou devem substituir importantes recursos didáticos. Mas, por que não, ensinar também com isso, dentro 


\section{per
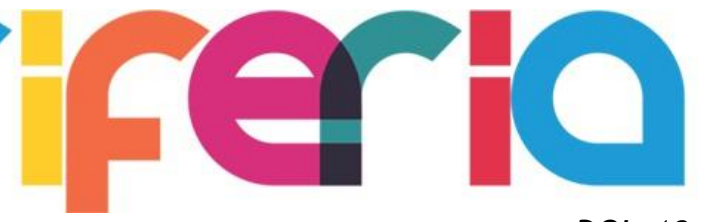 \\ EDUCAÇÃO \\ CULTURA \\ \& COMUNICAÇÃO}

DOI: $10.12957 /$ periferia. 2019.36408 de parâmetros que tornem este recurso uma ferramenta que aproxime professores e alunos em uma linguagem digital comum?

O que pode ser interessante é o uso dos mesmos como um recurso pedagógico para revisar ou mesmo apresentar conteúdo de maneira mais leve, que chame a atenção dos alunos para a aula e, a partir disso, professores possam inserir outros materiais. Em uma época na qual os recursos digitais representam também uma distração nas salas de aula, se associar ao mesmo, dentro de uma perspectiva com objetivos pedagógicos, pode ser um recurso interessante para romper barreiras, aproximando estudantes em salas de aula.

Deste modo, os memes podem ser um interessante recurso pedagógico a ser utilizado por professores e outros profissionais de ensino para criar um ambiente mais familiar aos estudantes, tornando a sala de aula um local onde os estudantes gostem de estar.

\section{REFERÊNCIAS}

BURKE, Peter. Uma História Social do Conhecimento II: Da enciclopédia à Wikipédia. Tradução Denise Bottmann. Rio de Janeiro: Zahar, 2012.

CASTELLS, Manuel. Creativity, Innovation and Digital Culture: a map of interactions. Revista Telos. Dossiê Telos. Fundacion Telefonica, n.77, out/dez., 2008. Disponível em:https://telos.fundaciontelefonica.com/telos/articulocuaderno.asp@idarticulo= 3.htm. Acesso em 14/07/2018.

GLEICK, James. A Informação: Uma história, uma teoria, uma enxurrada. Tradução de Augusto Calil. São Paulo: Companhia das Letras, 2013.

LÉVY, Pierre. Cibercultura. Tradução de Carolos Irineu da Costa. São Paulo: Editora 34, 2010. $1^{\text {a }}$ ed em 1999.

MARNARD, Dilton C. S. Memórias do Segundo Dilúvio: uma Introdução à História da Internet. Cadernos do Tempo Presente. Edição número 04, 2011. Disponível em: http://www.seer.ufs.br/index.php/tempo/article/view/2721/2374. Acesso em 28/06/2016 às 16 horas e 14 minutos.

PARISIER, Eli. O filtro invisível: o que a internet está escondendo de você. Tradução Diego Alfaro. Rio de Janeiro: Zahar, 2012. 


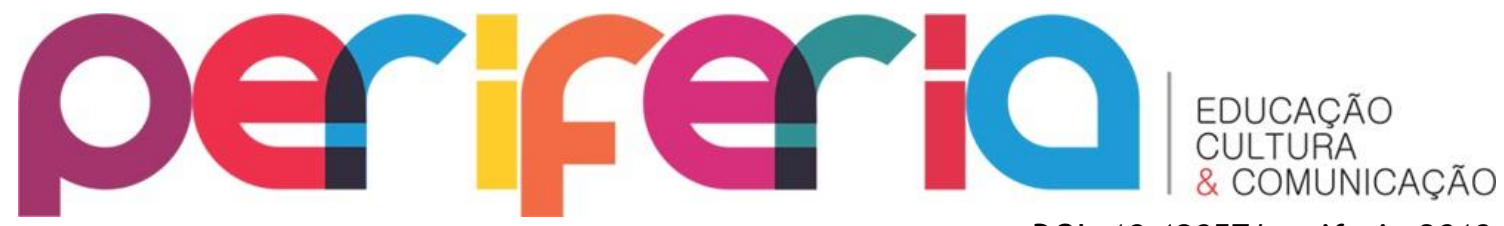

DOI: 10.12957/periferia.2019.36408

PRENSKY, Marc. Digital Natives, Digital Immigrants. Disponível em: http: / / www. marcprensky.com/writing/Prensky\%20-

\%20Digital\%20Natives,\%20Digital\%20Immigrants\%20-\%20Part1.pdf. Acesso em 09/03/2016 às 16 horas e 04 minutos.

SOUZA, S. E. O uso de recursos didáticos no ensino escolar. In: I Encontro de Pesquisa em Educação, IV Jornada de Prática de Ensino, XIII Semana de Pedagogia da UEM: “Infância e Práticas Educativas". Arq Mudi. 2007. Disponível em: < http: / /www.dma.ufv.br/downloads/MAT\%20103/2015-

II/slides/Rec\%20Didaticos\%20-\%20MAT\%20103\%20-\%202015-II.pdf>. Acesso em: 23/07/2018

\section{Sitiografia}

BBC Brasil. Portal de notícias. https://www.bbc.com/portuguese. Último acesso 30/07/2018.

FACEBOOK. Rede Social. http://facebook.com. Último acesso 30/07/2018.

FUNDAÇÃO TELEFONICA. Fundação realizadora de projetos sociais. http: / / fundacaotelefonica.org.br. Último acesso 30/07/2018.

MARC PRENSKY. Site pessoal. http://www.marcprensky.com. Último acesso 30/07/2018.

TECH TUDO. Portal de Notícias. https://www.techtudo.com.br. Último acesso $30 / 07 / 2018$. 